\title{
Is it Possible to Generate Development Starting from Communication?
}

\author{
Rosa María Alfaro Moreno ${ }^{1}$
}

\begin{abstract}
Communication, both intra-sector and among sectors, can generate dialogues and reciprocity and render development a public matter, i.e. a matter that pertains to all, including the media sector. However, it is still the case that we are faced with scattered social forces, unclear about their role in promoting inclusive, equitable and plural development. Those forces sometimes lack in democratic convictions or in significant social bonds among similarly minded groups. This article condenses years of reflection on our work at the Association of Social Communicators "Calandria", a Peruvian civil society institution created in 1983 as the point of departure to argue that citizens should be the protagonists of development in a relationship with other key players, from government, the business community and organized civil society.
\end{abstract}

Keywords: citizens, volunteering, social capital, alliances, accountability

\section{Introduction}

This question can be answered positively from several integrating perspectives: beginning with citizenship at the individual and collective level; from the shared support of civil society; by interacting with the existing political organization; via the engagement of a committed although still small part of the business community. Communication, both intra-sector and among sectors, could generate dialogues and reciprocity and render development a public matter, i.e. a matter that pertains to all, including the media sector.

However, it is still the case that we are faced with scattered social forces, unclear about their role in promoting inclusive, equitable and plural development. Those forces sometimes lack in democratic convictions or in significant social bonds among similarly minded groups. Research results published in 2009 showed that the newspapers of eight Latin American countries devote only $21.5 \%$ of their news items to social problems, and barely $13.7 \%$ to development ${ }^{2}$ (Alfaro Moreno, 2009). Yet, in spite of this state of affairs, development is slowly gaining in importance as a public matter both in Peru and in other Latin American countries, and thus beginning to have an influence on some policies or state reforms and on the education of the citizenry. The Millennium Development Goals have started being acknowledged, although not enough is known about them, and even if they are occasionally discussed in simplistic or frivolous ways.

This article condenses years of reflection on our work at the Association of Social Communicators "Calandria", a Peruvian civil society institution created in 1983. Such 
work has included several innovative experiences, such as e.g. the Civic Observatory of Social Communication (Veeduría Ciudadana de la Comunicación Social), significant experiences of civic journalism, and the participatory elaboration of ethical codes for the media in different cities throughout Peru. Some of those experiences have led to the implementation of commitments in local and multicultural spheres, with an emphasis on communication policies, accountability and civic vigilance. We will begin the article with a description of the context, and then move on to argue that citizens should be the protagonists of development in a relationship with other key players, from government, the business community and organized civil society.

\section{Citizens and Contested Powers: Adverse Conditions for Development and Democracy}

The democratic system allows and validates citizens' political impact, particularly through electoral processes. It is in the context of those processes that politicians reach out to citizens in order to get their vote, sometimes offering changes or improvements in exchange, and at times resorting to varied seduction strategies, often of a populistic sort. Within one electoral process and the next, however, elected politicians grow apart from citizens, who become less important to them once citizens have cast their ballots. Driven by the logic of power, those politicians avoid taking responsibility for their actions with regard to their voters. The commercialization of political relationships during electoral processes results in unfulfilled promises and societies that do not move forward. The low salaries paid by large businesses and the destruction of jobs add to collective outrage. That split between governments, politicians, businessmen and citizens produces a state of constant crisis that affects governability, with media usually leaning towards the more powerful. The distance among parties settles and grows as years go by and problems remain unsolved, aggravated by corruption and salary increases for those in government or successful businesses, while ordinary citizens stagnate, lose ground or remain excluded. Significantly, Peru's current president, Ollanta Humala, who took office in July 2011, ran for election with a slogan promoting the 'social inclusion' of all Peruvians. The logic of inclusion implies that democracy itself is at stake if it excludes citizens - exclusion can lead to collective rage. The lack of inclusive educational policies, based on regular dialogue and the adequate provision of quality services, has led society to keep to itself and doubt the state, which is considered a potential enemy. Citizens do not feel that they are part of the state: sometimes they'll raise their protests against it, and on occasion they'll seek to get rid of it by overthrowing it, but at the same time they'll need to ask favors from it. These conflicts and paradoxes need to be acknowledged. In the case of Peru, those citizens most excluded, such as e.g. indigenous peoples, are asking for opportunities for dialogue and claiming to be heard as a way to become protagonists. In other words, they demand an interactive communication that can somehow help lower the existing levels of corruption and make it possible to achieve mutual respect among parties.

Our societies are beginning to acknowledge their own strength and power, although in irregular ways: sometimes planned, at other times in the form of dispersing or disbanding moves that cannot find immediate containment. In some cases, the law is respected; in others, it is broken. In legal terms the importance of civic participation has evolved, 
resulting in normative progress (although not always leading to ethical and committed action), and the amount of electoral instances and calls for participation has grown. Latent collective power is growing, and it is possible to infer that consciousness about its strength is also on the rise. Individual power is obviously weak, given its democratic frailty. As collective power emerges and becomes more articulate, it hits the streets and resorts to every possible action in order to call attention to its claims and force solutions to them. This modality has grown both in Peru and in neighboring countries, at times even reaching the point of dethroning presidents, military and other authorities, and receiving almost regular press coverage (even with a focus on the disease rather than on its potential prevention). There are many examples of protests claiming e.g. a better educational offer, as has been the case in Chile in the past few months under the visible leadership of a young woman, Camila Vallejo. In Spain, young people are questioning politics, referring to themselves as "the outraged" ("los indignados") - a feeling echoed in several other parts of the world throughout 2011. In Peru, indigenous citizens have argued that the state should listen to them for many years, and it is finally beginning to happen. The search is for an inclusive form of communication that starts with governments listening as a step towards seeking change. Citizens want to exercise not only their right to vote, but also their right to voice.

In a survey undertaken by "Calandria" in August 2011 among 2,400 Peruvian citizens - still unpublished at the time of writing this article - we found outstanding references to wanting to be important within society, i.e. taken into account in the decisions affecting the country $(41.75 \%)$. Moreover, citizens want to be acknowledged and valued by the government (25.6\%). In other words: $67.5 \%$ of those interviewed wish to belong to the country, i.e. to be considered and treated as citizens. The collective desire to belong is strong, suggesting the possibility of further personal commitment. Interestingly enough, these expressions arose after people had voted for president, at a time when the majority said they respected the candidate elected to run the country. Such a strong and steadfast spirit could pose an important problem to those elected if they cannot relate with, and work with, the country's citizens. Unless the communicational and governmental relationship between citizens, politicians in office and business executives is clearly defined and enhanced, there could be great disenchantment, and perhaps even violence.

Citizens seem to value themselves more highly in the face of politicians, although at the individual level populist favors may still rule, and despite cases in which violence is promoted to support particular interests. While their relationship with politics still implies confrontation, they are observant and looking for opportunities to have a role. This is not easy in a context in which both reality itself and media representations discriminate against them -in the case of the media, by reducing them to abstract viewers measured through ratings. The inability of political parties to solve peak levels of poverty, unemployment and lack of recognition has led citizens to adopt new emergency strategies. As a consequence, the limits of politics are being blurred. In Peru, political parties are dying out.

In this context, the search for social recognition continues, both as a struggle but also from the emergence of popular cultures, imbued with new sensibilities that suggest it might be possible to develop cultural industries based on them. These new sensibilities are appearing on TV as part of successful series, comedy shows and massive concerts and, even if with some distortions, they reflect Peru much more than they reflect politics 
as such. Politics has increasingly become a satire of people's hopes and joys. Among people, there is eagerness to participate and higher self-esteem, but not always a consideration of citizenship or democracy as a legitimate system for all. That is to say, we Peruvians are still politically contradictory, but life beats within us, and therefore we have an unusual opportunity to push for new and relevant social, political, economic and cultural changes.

Despite having a large (or even excessive) amount of media, Peru is not a country in which the different sectors of society communicate well with each other. Data from 2011 indicates the existence of more than 2,500 legal radio stations and 1,250 TV channels. That is, we have many media, but those media do not engage in dialogue with citizens. The desire to be relevant and capable of expressing opinions is present among people, but the everyday media reality, in which citizens only count as rating percentages, is discouraging. The media could take on a new role, coming closer to citizens and to civil society and querying political parties and figures. They could add to the challenge of making Peru a better country through the ways in which they construct and address the country's main problems, rendering those problems public and generating pertinent debates. Puzzling out what brings us together and what sets us apart is a communicational challenge of an inclusive character. We still need every sector to exert political pressure towards an inclusive country. In this scenario, the everyday practice of communication with an educational purpose might lead us to better futures.

\section{Citizens Learn to Put Forward Proposals and Discuss with Others in Dialogue}

Civil society usually sets itself in motion starting from existing social problems. Its inspiration comes from ethical principles for social change, aimed at goals to be fulfilled or achievements to be conquered. This approach, which has represented a virtue of civil society, was useful at a specific point in time to establish diagnoses of social reality and to formulate concrete projects towards change. Such diagnoses and projects, however, led to isolated transformations, focused on specific topics and specializations. Several civil society institutions engaged in a different approach and devoted instead to empowering social subjects, i.e. organizations or movements. They stressed the social and political relevance of those collective social subjects, but disregarded the importance of change and learning at the individual level. This approach corresponded to a period of workshops, schools, leadership training and preparation for entrepreneurship. Both formulations are grounded in a romantic view of change, tackled from a specific topic instead of from the perspective of subjects and their realities. Such a view of change led to battles for what things should be like, instead of work towards what was possible. To which extent our practices made a substantial difference and worked as long-term paths was always at issue. To give an example, the above-mentioned approaches made it impossible to bring together topics and problems, because we stuck to the modern disciplinary approach that segments types of knowledge, drawing hard borders among them and preventing an understanding of subjects' complexity and their ways of making sense of social reality.

We rarely start from what others are, think and feel. We only take into account what is general about social situations, and not how they are perceived through multifaceted subjectivities. We still use fundamentalist views, without admitting to the fact that at 
present subjects' identities are no longer unitary or coherent, and missing out on a plurality of views and interpretations of reality and of ourselves, in a dynamics of resistance, distancing or complicity with power. From this perspective, the subject is always unstable: "We can thus conceive the social agent as constituted by an ensemble of 'subject positions' that can never be totally fixed in a closed system of differences, constructed by a diversity of discourses among which there is no necessary relation, but rather a constant movement of over-determination and displacement" (Mouffe, 1993/2005: 77). The assumption that identities are fixed and harmonious as a consequence of one's social class, culture and education could be a serious mistake. When we call for participation, there is no good or bad; rather, there are errant citizens with differentiated and changing positions. To give an example: in certain situations they'll be leaders, and in others subordinates, among many more differentiations. Inner contradictions and conflicts may play a role for or against intervening. Starting from the other in order to invite his or her participation implies invoking their senses and capabilities to act. That is communication: to promote an understanding. We should also take into account the fact that our people need to be represented and acknowledged symbolically as equals and as capable of transforming reality, admitting the existence of differences and appealing to citizens in efforts aimed at helping them progress. In order to have an impact on society and on politics, we must start from where people are, seeking to convene them in integral and diverse ways, so that political action is educative of itself.

Social bonds are usually broken, and reconstructing them implies not only a rational struggle, but also imagination and communicational sensibility. Citizens want and demand concrete changes, but producing such changes is not easy. In that context, the role of a communicator is not to preach, but to promote reflexivity and self-appreciation, to listen, to generate debate, to promote mutual recognition, and to encourage imagining that a new society is possible. Rather than embarking upon abstract proposals, we should engage in those that are viable (even if gradually) and can mobilize citizens towards reconstructing the society that we live in. We need to start from the people, listen to them and make an effort to understand them. Much can be learnt in this way. Communicating can build trust and self-appreciation. Processes are important not only because they make it possible to advance gradually in an adequate direction in terms of leadership and pedagogy, but also because they help us think and redefine our own understandings of what we want to achieve and what we are doing. Civil society has led us to believe that the world is objective, and thus made us prone to disregarding what's new when in need to adjust or change direction. All programming should be flexible in terms of strategies, and rigorous when it comes to evaluating what is produced along a process, taking into account what many people can contribute. Some international cooperation agencies cannot understand the need for flexibility, ruled as they are by expenditures and the measurable delivery of activities. Many of those of us in the civil society sector suffer when we must deal with cooperation agencies worried about how many people attended a workshop or a class, and fixated on the fulfillment of financial allocations as planned at inception, even when reality tells us that one activity is no longer necessary for a process to move forward, and could be substituted for a different one. Reflecting upon this leads us to define the citizen not as a victim of the social system or as the 'the good guy' in the story, but rather as someone who can modify reality by participating emotionally, creatively and intelligently, thus helping solve his/her problems and those 
of others, by seeking political alliances, be them readily available or to be constructed. In this regard, it is useful to take into account and promote the increase of the social and cultural capital that we have at our disposal ${ }^{3}$. We are confronted with an active citizen with the capability to put forward proposals and exert an influence, and not merely protest. The task ahead then becomes to facilitate the path towards having a bearing on authorities, towards social organization and towards self-improvement of citizens' political capability to engage in dialogue.

The experiences of citizen journalism that have been taking place in Peru are resulting in specific important changes in some locations. In the process, citizens become subjects that make contributions towards a public agenda. For example: journalists in a rainforest area asked citizens what their most severe problem was, and people responded that water contamination in their lagoon was harming their children and leading to deaths precisely where those kids enjoy swimming and playing. Next, the journalists set about understanding the causes of water contamination, many of which are the consequence of governmental and business irresponsibility. Once they identified the causes, they organized a public debate to discuss suggestions for change put forward by the people. Citizens stated that they learnt much in this process, starting with how the journalists listened, developed a sense of the problem, and wrote about it in the local newspaper. They participated themselves, but moreover, finding what they proposed expressed in the media led to a change in their self-appraisal. Proposals for change in turn resulted in gradual improvements of the quality of the water and to a commitment from the regional government. In other words, a communicational process took place in which the regional government listened and pushed for changes based on the support of thousands or hundreds of citizens. Citizens moved forward, from stating claims to having a role in raising concrete proposals for transformation and exerting social pressure with a social and democratic change perspective (Alfaro Moreno, 2005: 54-65). This kind of impact is possible only when citizens and the organized civil society form a connection with the support of the media and journalists.

\section{The Challenge of Building Identities}

References to globalization and to the large economic powers as the causes to blame for the problems we are experiencing belong to a discourse usually paired with defeat. Such defeat triggers denunciation and grievance as the only foreseeable responses, thus accentuating our political impotence. Alternatively, the response is confrontation or war, aimed at overthrowing power - be it relative and circumstantial power, or the world's power centers, as targeted by some sectors. From these perspectives, transforming society and rendering it fairer and freer is impossible, and communication fails to introduce an alternative path.

Submerged in this pessimism, which depletes hope, the constant criticism of everything becomes a "way of life", which can lead to evading humanity's responsibility toward itself. In other words, such a deprecating attitude stands in the way of citizens developing their political will to make a difference. We know that we are seeking for justice and freedom; but how to achieve them, and in which direction we should be headed to do so, are questions for which we will find answers as we move ahead. It is necessary to learn to live with uncertainty in order to begin to gradually unravel it. This 
search calls for a strong ethics that will enable reflexivity and self-questioning. Crucially, it becomes incumbent upon us to create better life conditions, and a social force that develops and grows. And this, in turn, is only possible if we engage with politics and promote communicational public influence.

A strategy should identify cracks, conflicts and windows of opportunity and specify the challenges we face, such as for example the fact that the media have been found guilty of corruption, or that audiences are significantly dissatisfied with the media. At the same time, it is important to diagnose the capabilities of civil society and the other sectors engaged in these, in order to work towards development and an ethical coexistence. We cannot go beyond what we are capable of. In Latin America, the existence of democracy is in itself a factor in favor of our intervention. Opportunities must be reclaimed, and entrepreneurs are right when they say that even failure can be an opportunity to turn a problem around and move forward in a different direction. From this perspective, paradoxes are more fruitful than contradictions.

If we understand changes as challenges to be implemented, a discourse that proposes can mobilize much more than one that criticizes or condemns. If critique must be raised, it should be put forward in a way that strengthens arguments for change and motivates action. It is important to work with symbols and ideas of the future that allow us to imagine what we all will win if we achieve our goals. In societies that are deprived of hope, it is essential to give clear indications of the relevance of what we do. This is probably the reason why the motto of the women working with soup kitchens in Peru (Comedores Populares), "protest plus proposal", was so successful in our country. In other words: in order to generate transformations, critique and questioning are not enough -we must imagine and specify new paths, thought out and discussed by citizens themselves. The capability to articulate what needs to be done implies a major educational process: it is difficult but necessary to transition from being a victim who complains to becoming actively involved in change. Having a bearing on authorities, political parties and other sectors gives us visibility as innovative protagonists and shows it is possible to participate in change.

\section{Civic Observatory: Protest Plus Proposal, or the Opportunity to Exert an Influence on the Media}

The Civic Observatory of Communication was created in Peru towards the end of the nineties, when corruption within the country's media was publicly unveiled by a Peruvian TV channel. A video showed the owners of certain media outlets receiving money from the government in exchange for avoiding questioning. The news showed that freedom of expression was up for sale, and triggered a scandal, since it became obvious that money belonging to all Peruvians was being used to secure the results of an upcoming electoral process. The crisis was in turn a favorable moment to foster civic involvement.

Following the discovery, a complex process of debate and recommendations took place among a group of communicators, politicians and lawyers. In parallel, we started using surveys to gather the views of citizens, who were outraged. Eventually, we decided to work towards an audiovisual media law, and we submitted a proposal to Parliament entitled "A Civic Legislative Initiative" (Una Iniciativa Legislativa Ciudadana), backed by 85,000 signatures, most of which were deemed valid, and by letters from different 
parts of the country. We were supported by communication and journalism students from several universities, as well as students from other disciplines. Street debates were organized in order to motivate civic participation. And although Parliament did not adopt the whole of the proposal, the effort implied a step forward. Political parties, media owners, and journalists imbued with ethical concerns also took part.

Once the new law was ready, including transformations that were not precisely positive, civic commitment was sustained through a yearly "Media Parliament" ("Parlamento Mediático"), freely constituted by citizens. Surveys were undertaken in advance of each yearly session, and the results served as input towards a debate about the quality of the media on offer, which took place in the Parliament building. Best practices were awarded, and citizens put forward their proposals for what needed to be changed.

The Observatory was criticized on rationalist grounds by those who understand ways of exerting influence and of acting from the perspective of hard and ambitious macrocategories. Criticism came especially from civil society itself. Civil society institutions not always understand communication or are capable of communicating beyond simplistic diffusion. Some questioned our social base, and argued that it could only exist if organized in a representative manner, with leaders, regular meetings and communiqués. Having an ideology was also deemed a prerequisite. From that perspective, our influence was not considered significant. Others worried about the diversity of the contributions put forward by the participating organizations, uncomfortable in the face of difference. In fact, some organizations provided moral support, others replied positively when asked for specific contributions, and a few shared common tasks.

Our strategy was in fact not to ask the same from all. In some cases, we settled for the minimum significant contribution that could be offered. Based on our experience, it is not true that homogeneous commitments from all parties are necessary. A strategy that combines the different contributions that are feasible, accepts a diversity of perspectives regarding a given process and welcomes gradual progress can actually work. We did face some intransigent, unchangeable questioning, as well as other attempts to force certain moulds on the situation. We acted like strangers, in a way, in that we moved 'here and there'. The idea that we should identify what seemed viable before we decided how to act did not interest many, but at the same time others became interested in the concrete possibility to achieve progress, even if small. Moreover, having a new democratic law was already a success for the country: until then, the saying had been that "there is no better law tan the law that does not exist". Our passionate claims were allowed and appreciated, but barely understood: our acceptance and embracement of conflicts as signs of the possibility of transformation were in fact questioned. And yet, our point of view is more valued today than it was initially.

Curiously enough, society is seen as a homogeneous and structurally organized totality, without taking into account the richness of existing conflicts and counter-positions as the substance of change. Democracy does not imply homogeneity or a paradise of all-encompassing understanding. Rather, it implies visibly addressing injustices, rifts and contradictions through dialogue and proposals for change. The fact that a given established order in turn leads to disorder is rarely accepted, but should be manageable. Likewise, we should be aware of the fact that, in the face of a strong power, there are counter-powers that can function as strategic sites for action aimed at shaking those parts of the system that seem immovable. 
Rather than seek homogeneity, our aim was to find what there was in common among heterogeneous parties, accepting what each institution could contribute from its position and based on its area of specialization. In other words, we did not situate ourselves among those 'of a like mind', but sought a meeting ground with others, such as e.g. business executives, politicians from different parties, important personalities, youth groups within academia, and some teachers. We needed to be more encompassing and comprehensive in order to find people and institutions with the knowledge and capabilities required, that not everybody possesses. In the process, we were faced with having to learn new things and question ourselves.

The relationship that we established with the Peruvian National Association of Advertisers (ANDA, Asociación Nacional de Anunciantes) was crucial. It was mutually beneficial and led to learning. The advertising sector opened doors for the civil society sector, and connected us with other well-meaning economic sectors in the country concerned with ethics. We also worked with some political parties, which overall are currently lacking in direction and in danger of disappearing. Moreover, other institutions and organizations need to be connected into a network, and organized at least through minimal coordination, such as e.g. parents' associations, universities, popular culture groups, volunteers in the health sector, in order to promote an open mind in the context of differences.

Perhaps the alliance most difficult to achieve was with the media outlets, which questioned our views on regulation, self-regulation and quality journalism. Some media irresponsibly sentenced us to silence, while others drew on our critiques and suggestions. We searched for those ready to listen and collaborate without expecting monetary compensation, and we networked with them, thus generating links among the scattered civic powers of society.

Lobbying is an insufficient, ineffective strategy when we face the pressure of stronger powers well endowed with money and other resources. Rather than aim for economic or political negotiation, from an ethical perspective we should appeal to the common good, the advancement of democracy and society's awareness, aiming for citizens' support of alliances and networks. The media do not necessarily respond to being questioned by public figures or journalists, but react to audience ratings. Communicative processes trigger dialogues and debates, lead to agreements and make it possible to identify disagreements, allowing the poorest or most disadvantaged to have a role towards transformation.

\section{Volunteer Work as a Way to Mobilize Social Capital}

An ethical concern with justice calls for finding those willing to volunteer their support because they share our viewpoints and want to improve the state of things. There are always citizens willing to participate and do something for their country regardless of electoral or economic benefits, or of political party mandates. Their participation should allow them to learn and to enrich their cultural and ethical capabilities, and will make it possible for civil society to better understand the people, the country and any ongoing changes. The actions proposed to volunteers need to be interesting and lead towards their positive involvement with social matters, allowing internal debate and giving space to suggestions for the change of strategies or approaches. 
Aware of the generosity of volunteers, we should allow their fluctuating participation rather than impose absurdly strict commitments. This was the approach in the case of the Observatory, particularly when working with young students on civic consultations across the country. Over time, the opportunities for debate and training attached to volunteer work led those young students to recognize other areas for action and thus undertake other initiatives, such as e.g. the promotion of curricular changes and teaching styles within universities.

This type of work mobilizes people, who become better listeners and learn to answer questions and to collaborate when their suggestions for change are sought. Importantly, knowing that work is voluntary in a society so keen on commodifying everything helps promote receptivity and an open mind among people.

Moreover, voluntary work energizes those involved, triggering enthusiasm. Dialogue is mutually enriching and can lead to increased commitment by appealing to passion besides promoting rationality. In the process, an understanding of citizens' right to communicate is co-constructed with them.

\section{To Have an Influence, or to Make a Difference? And for What?}

In facing these questions, we must acknowledge that citizens are often skeptical about the possibility that things might change for the better. Many believe that the only way out is to seek individual progress, competing against others for scarce resources, as seen within the government, political parties and several institutions -including NGOs. This secret culture remains unspoken of, but is recurrently practiced and legitimized, sometimes with brutal force. In order to promote new social ties, we need to restate agreements among citizens, government, businesses and civil society in a more articulate, yet diverse manner. At the time when they were established, the Peruvian consultation round-tables were an important step forward; however, at present they have become insufficient: we need further links among social sectors in order to decide what it is that we want, how we will achieve it, and which responsibilities we will assume. Commitment to the same goals is necessary, not as a formality but as part of a converging interest in making Peru a better country. Differences in terms of what each sector can contribute should be allowed, specifying the concrete activities to be undertaken. In this way, short-, middle- and long-term goals that range from solving concrete problems to working towards more structural changes can coincide in terms of the political imagination, and generate hope.

We need to be clear about what we want to achieve now and what we want to achieve later on. How to achieve those goals will become gradually clearer in the process. The tendency is to seek goals that are grand, ambiguous, moralizing and non-viable, and thus disconnected from the search for concrete solutions that people claim. Overcoming poverty, achieving gender equity, and enforcing human rights are issues that belong to a complex whole, and cannot be tackled if we distance our action from the concrete reality that requires solutions. Our political will to have an impact must be translated into concrete acts.

It is necessary to regain trust in collective power. For example: through the experiences of civic journalism undertaken by Calandria, first alone and then for a brief period with a consortium of universities - Cayetano Heredia, Universidad de Lima, Pontificia 
Universidad Católica, Universidad del Pacífico - we pushed local authorities to take responsibility for the health problems considered a priority by the population. The amount of institutions and people committed to finding a solution to those health problems had an impact on local governments. The capability to retrieve the different forms of social capital of a locality is very important, be it organizational or professional capital, available consultation mechanisms, individual support, local media, etc. The public spaces mobilized must be diverse, including the street, meeting points, large and small media, i.e. every space that interconnects us.

Once we start intervening and influencing, we earn the right to monitor and to claim accountability. In many cases, these democratic tasks are undertaken without having taken any previous action to try to change the sector that we expect to have an influence on, and without having enough experience and knowledge regarding the matter on hand. As a consequence, some monitoring initiatives fail. Having the capabilities needed in order to analyze what we are monitoring is necessary, and in this regard, research can be helpful and expertise is welcome. Monitoring will lead to change if we can put forward proposals that are feasible.

We require newly configured social pacts among politicians, civil society, the market and citizenry. Such social pacts must be built gradually, in concrete ways, by connecting them to an overall idea of changes to be achieved and by seeking to achieve specific results. For example: we could focus on solving the problem of water contamination, increasing citizen's security, improving child nutrition, or opening up specific employment possibilities for a given area. People rarely get involved in macro-social plans designed by experts, either because they are too general or because their characteristics have not been communicated or discussed at large. Conversely, when people have participated in the process of producing a proposal, they tend to consider it their own, and thus engage and feel committed to monitoring, which in turn improves the chances of materialization.

\section{The Supremacy of Public Matters Based on Educational Deliberation: Towards Communicational Public Policies}

The public realm does have an influence on society, in that it embodies what is visible and what is common. People connect to the opinion of the majority. Exposure and public discussion lead to seeking minimum agreements. There is a wish to see, hear or read what everybody has access to, which changes the public realm into a field of representation and recognition. Efforts to achieve visibility are made, despite experiencing contempt, derision or the occasional violation of our rights. There is a collective anxiety to be included, to be present, in what is visible to all. In current societies, complex as they are, direct organizational forms are insufficient to allow us to connect and belong. Democracy presupposes the existence of public interests, spaces, agendas, opinions and pursuits. Coexistence is not possible if a public realm does not exist. Therefore, in the context of present democracies, having an influence on the production of a public realm is a highly relevant task for communicators, imbued with an ethical meaning.

To be present in the streets but also in the media are ways of exerting significant social pressure. Presence within social networks is also important, although the impact of such presence not always is lasting. Situating the problems experienced by citizens as public matters that must be prioritized in the agenda has a political impact much more signifi- 
cant than any lobby efforts. To do so, it is important to generate bridges between civil society and media. In Peru there is a lack of debate, which tends to be misunderstood as either confrontation or the monologic presentation of people with differing positions who do not address each other. The media require that we develop the capability not only to mobilize citizens, but also to translate our priorities and aspirations into attractive and concrete possibilities to intervene. We must develop new ways to make controversies see the light of day that allow mutual listening among sides. Learning to deliberate and to reach minimal agreements is not customary or culturally ingrained in the country. Therefore, the challenge is not only to get the media to refer to what we do, but also to set up a 'cultural factory' that produces dialogue, debate and agreements with the media as the engines of diverse interlocutions.

As communicators, we must situate our relevance and demonstrate that we are good at what we do. For example: it is important to clarify if we are acting as sources of information (and that we are prepared to do so), or alternatively as protagonists of actions, as monitors ready to denounce what is wrong, as the proponents of innovative and participatory changes, as opinion leaders or campaign managers. The issues, the methodologies used, the actors involved, the creative capacity displayed-they all matter. The identity of what we do must be lucid.

What we expose must be framed by concrete reality and the horizon of what can be possibly built. General discourses oriented towards obligations that seem intangible are not useful. Debates must be fleshed out, leading to agreements that can respect disagreements. Messages that both challenge and convene are essential: invitations to transform concrete matters act as calls for personal and collective change, leading to political development. Such messages require that we go beyond preaching, that we set sensibilities in motion and that we promote trust.

It is also important to define our goals, methods and approach to economic transparency, in order to prevent controversies: we must explain what we are; what we seek; the ways in which we intend to act; the money we count on, where it comes and how it is used; whom we are and are not working with. To generate trust is as important as a quality proposal. The challenge ahead is for every institution, every organizational system, every locality to have clear public communication policies that lead to social pacts based on the constant practice of tangible and collective deliberation.

Also significant are our efforts to have an influence on the state and its different components, not only because it is there that one dimension of political power lies, but also because the state is ours. It belongs to us as citizens, and therefore we have the right to have an influence on it, and the duty to collaborate in its due performance. As is the case in other countries as well, the Peruvian state has not developed public communication policies, resorting instead to marketing and press strategies. Much remains to be done, from a communicational approach, to strengthen democracy and to publicly consolidate development proposals by submitting them to an open plurality of opinions.

Interestingly, many university students volunteered to participate in the experience of the Observatory, out of their own initiative, and their involvement in turn led to the engagement of others, in a chain reaction. Those students got to know poverty up close and learnt about their communicational capabilities. Their participation tells us that not only institutions matter, but also people ready to show respect and share a commitment to honesty as well as a long-term view of how the country could be reconstructed. Through 
the Observatory we also discovered that some business companies are truly imbued with a sense of social responsibility, while others refuse to assume such responsibility. We faced several problems, but learning to tackle those problems was in fact an essential part of the process. The involvement of those people who individually symbolized our principles was important in order to have public impact, in the context of the collaboration between universities, civil society and citizenry. In turn, these people learnt much about communication and popular cultures -both their richness and their weaknesses. Self-reflexivity and ethics were undoubtedly relevant aspects of the process.

\section{Notes}

1. Rosa María Alfaro, Professor of Communication at the Universidad de Lima, Peru, is founder and former director of the Association of Social Communicators "Calandria", and founder of the Civic Observatory of Social Communication. E-mail: ralfaro2006@yahoo.es

2. Translator's note: the study, implemented in eight Latin American countries through the Latin American Network of Media Observatories, sought to identify the ways in which human development (following Amartya Sen's conceptualization) was covered in national printed newspapers. The focus was news about national economic and social development, particularly coverage given to serious economic and social as problems to be solved and related proposals and policies for change. The conceptualization of development that guided the analysis was multidimensional, and took into account social, economic, political and cultural outlooks as well as local, national and international scales. The Millennium Development Goals were taken into consideration as a general frame of reference. (Alfaro Moreno, 2009: 13-21)

3. In this regard, it is interesting to take into account the perspective put forward in Kliksberg, B. and Tomassini, L. (2000).

\section{References}

Alfaro Moreno, Rosa María (2005) La salud, un asunto público. Lima: Consorcio de Universidades.

Alfaro Moreno, Rosa María [compiladora] (2009) ¿Desarrollo? Encuentros y desencuentros entre medios y ciudadanía. Perú: Observatorios en red/Calandria.

Kliksberg, Bernardo y Tomassini, Luciano [compiladores] (2000) Capital social y cultura: claves estratégicas para el desarrollo. México: BID, Fundación Felipe Herrera, Universidad de Maryland, Fondo de Cultura Económica.

Mouffe, Chantal (1993/2005) The return of the political. London: Verso.

Mouffe, Chantal (1999) El retorno de lo político. Comunidad, ciudadanía, pluralismo, democracia radical. Barcelona: Paidós (página 110). 